\title{
Ecos Mundiales del Golpe de Estado. Escritos sobre el 11 de Septiembre de 1973
}

\author{
Alfredo Joignant y Patricio Navia \\ (compiladores)
}

\author{
Ediciones Universidad Diego Portales, Santiago, 2013, \\ 379 págs.
}

\section{Mauro Basaure ${ }^{1}$}

Universidad Andrés Bello, Santiago, Chile. Email: Mauro.basaure@gmail.com

La lectura de Ecos Mundiales del Golpe de Estado. Escritos sobre el 11 de Septiembre de 1973 nos vuelve a aguijonear el intelecto con cuestiones claves que destacados intelectuales extranjeros se plantearon a propósito de los antecedentes y del destino del proyecto socialista de la Unidad Popular. La agudeza de los compiladores, Alfredo Joignant y Patricio Navia, se pone en juego no sólo en una larga y muy rica introducción ("El golpe a la cátedra. Los intelectuales del primer mundo y la vía chilena al socialismo” (pp. 11-52)), sino que también en la propia selección de los textos y en el modo de agruparlos.

La primera parte, “Chilenos contra chilenos” (pp. 57-181), comienza con el artículo de Alejandro Portes — "Radicalismo de izquierda en Chile. Examen de tres hipótesis” (pp. 57-80), que puede entenderse como una radiografía sociológica de las precondiciones de la vía chilena al socialismo, esto es, del particular fenómeno de que, en el marco de varias décadas, un radicalismo de izquierda se había desarrollado no desde fuera sino que desde interior mismo de la institucionalidad democrática. El artículo que sigue, "Capitalistas en crisis: la clase alta chilena y el golpe de Estado del 11 de septiembre” (pp. 81-99), escrito por Richard Ratcliff en 1974, intenta poner los términos causales del golpe de Estado: se trató de una reacción de la clase alta dominante, a la acción de la UP, que logró constituirse en una amenaza cierta al orden capitalista imperante. El apoyo de las clases medias, de EEUU en el marco de la guerra fría, del PDC, entre otros, resultan todos ellos, elementos de orden más contingente. El golpe nunca tuvo otro objetivo que reinstaurar el imperio del capital largo plazo, para lo cual era necesario extirpar el radicalismo de izquierda y la posibilidad de que resurgiese. Su objetivo no fue la reinstauración de la institucionalidad democrática, de ahí no sólo su carácter politicida sino que también la exclusión de la DC del proceso post-golpe ${ }^{2}$. Los dos artículos que siguen van de la mano: el segundo revisita las tesis del primero. En el artículo de Guillermo O’Donnell — 
publicado en 1978 y titulado "Reflexiones sobre los patrones de cambio en el Estado burocrático-autoritario” (pp. 101-144)— también está presente la lógica causal acción y reacción vista en Ratcliff: la variable grado de amenaza sentida por las clases dominantes influye en la variable grado de cohesión de ellas, el grado de alineamiento e involucramiento de las fuerzas armadas y, con ello, el cómo se responde a la subversión, tanto a nivel del grado de represión contra los sectores populares como del grado de ortodoxia de la afirmación de un proyecto socio-económico capitalista. Este juego de variables generaría las diferencias entre los Estado-BurocráticosAutoritarios (EBA) en América Latina. Karen Remmer y Gilbert Merkx, en su artículo de 1982, titulado "El autoritarismo burocrático revisitado” (pp. 145188), revisan críticamente la tesis de O’Donnell: para explicar dichas diferencias, dicen ellos, es necesario relevar variables o factores post-golpe, propiamente políticos y no pre-políticos (grados de amenaza al orden). Las particularidades de los diferentes países, sus tradiciones políticas y los propios hechos post-golpe tendrían mayor peso explicativo de los diferentes patrones de represión y política económica, alineamientos políticos, etc. que se dieron en América Latina ${ }^{3}$.

Bien elegido está el título de la segunda parte, "La elite polarizada" (pp. 191-272). En ella Joignant y Navia reúnen dos artículos. El primero de ellos es de Henry Landsberger y Tim McDaniel y se llama "Hipermovilización en Chile, 1970-1973” (pp. 191-232)). Publicado en 1976, este estudio trata ya no sobre los enemigos externos de la UP, sino que sobre sus "enemigos internos”, los propios trabajadores. En particular, el sector ultraizquierdista de la clase trabajadora habría complicado a Allende no sólo por las acciones ilegales acometidas sino que además porque, con ello, le entregó a la oposición la justificación para decir que el gobierno había perdido el control y que el caos y la guerra civil se hacían cada vez más inevitables. Los procesos revolucionarios que han sobrevivido, dicen Landsberger y McDaniel, han tendido a apoyarse inicialmente en las masas para después desmovilizarlas y ponerlas bajo control. Pero Allende no sólo no restringió las libertades políticas de sus enemigos externos; tampoco restringió las de sus enemigos internos. "La opinión pública y el desplazamiento del gobierno chileno hacia la izquierda 1952-1972” (pp. 233-272) se llama el artículo escrito por James Prothro y Patricio Chaparro. La tesis de la izquierdización de la sociedad chilena debe ser revisada: tuvo lugar básicamente en las elites políticas, pero hubo un hiato entre ellas y la cultura política de los ciudadanos de a pié o de aquellos trabajadores no insertos en las redes comunicativas de la ideología ${ }^{4}$. Aparece así un nuevo flanco de debilidad de la UP, a saber, su carácter elitista o su falta de base popular.

Nuevamente son dos los artículos que Joignant y Navia seleccionaron para la tercera parte del libro, titulada "El golpe vino de afuera". El primero es de Paul Sigmund, “El 'bloqueo invisible' y el derrocamiento de Allende” (pp. 275-293). Rápidamente desmentida por el propio congreso de los EEUU, la tesis de Sigmund ${ }^{5}$ fue que el bloqueo de este país hacia Chile no existió y no fue parte de la fórmula del derrocamiento de Allende. La ayuda económica del bloque Europeo y Norteamericano habría disminuido 
muy poco y su disminución se explicaría más por la simple y pura racionalidad del sistema económico — - esto es, en función del simple hecho de que Chile se había convertido en un "cliente riesgoso”- , que por la sucia racionalidad política de la guerra fría. El segundo trabajo de esta parte, de Kyle Steenland, "El golpe de Estado en Chile” (pp. 295-322), publicado en 1974, viene a corregir correctamente lo dicho por Sigmund, aunque en un punto, el de la muerte de Allende, también ha sido ampliamente desmentido. Steenland afirma ampliamente la tesis de la intervención de EEUU hasta el punto de señalar que, además del bloqueo, la CIA participó incluso en los últimos detalles del golpe, incluyendo la complicidad en el asesinato directo de Allende a manos de militares.

En la cuarta parte, llamada “La izquierda haciendo Historia” (pp. 325379), se agrupan tres artículos y una discusión entre Andrew Zimbalist y Paul Sweezy (335-347), que tuvo lugar durante el gobierno de la UP. Uno de esos artículos es del propio Sweezy: “Chile: la cuestión del poder” (pp. 325333). Publicado en diciembre de 1973, él escribe como quien sabe que la historia le ha dado la razón y se la ha negado a Zimbalist, quien, en dicha discusión, defiende como políticamente correcta la estrategia institucionalista de Allende. Para Sweezy, en cambio, el golpe sólo vino a confirmar lo que él venía afirmando en dicha discusión y que, después del golpe, aparece como más que obvio, a saber, “que no existe una vía pacífica al socialismo”. Con ello él no quiere decir que la violencia sea el único camino, sino sólo que en algún minuto la confrontación abierta con quienes defienden el dominio del capital resulta una cuestión inevitable. En ese minuto se define siquiera la posibilidad de arrebatarle el poder a la clase dominante. La tragedia de la UP se debe a que ésta nunca resolvió el problema del poder. Fue gobierno, pero estuvo lejos de tener el poder. Ni siquiera habría tenido una estrategia para hacerse de él.

El texto que sigue es de Eric Hobsbawm y fue publicado en el mismo septiembre de 1973. Tiene por título “El asesinato de Chile” (pp. 349-352). Chile fue asesinado y sus asesinos son responsables, así se puede leer lo planteado por este conocido historiador. El verdadero experimento, dice Hobsbawm, consistió en probar si la clase dominante iba a ser capaz de atenerse a la legalidad y a la constitución ahí donde ya no podían usarla para la defensa sus intereses, pues la UP se los había impedido. Como muchas veces en la historia, dice Hobsbawm, la clase dominante no pasó la prueba. El golpe no sorprendió, no porque se impuso la imposibilidad lógica del socialismo sin violencia, sino porque el espacio histórico para una salida institucional fue conscientemente imposibilitado por el golpismo; porque la clase dominante forzó la marcha hacia un escenario, el de la violencia, donde sabían que iban a ganar y que Allende trató de evitar, porque no dudó de que así sería.

El texto que cierra la cuarta parte, y con ello el libro, es del historiador y sociólogo británico Ralph Miliband. Publicado en octubre de 1973, tiene el mismo título que el trabajo de Steenland: "El golpe de Estado en Chile" (pp. 353-379). En coincidencia con Ratcliff, Miliband señala que, en la mis- 
ma medida que la UP fue una amenaza real para la clase dominante, en esa misma medida se debió contar con que ésta dejara la "lucha de clases" tradicional —es decir, de una lucha en el marco de la constitución- y pasaran a una "guerra de clases", esto es a una forma de lucha más allá de la institucionalidad. Pero Allende insistió en la vía conciliadora y constitucional, y mientras más lo hizo, más creció la seguridad y la audacia de sus enemigos. Allende trató de evitar la guerra civil con el mismo ahínco que sus poderosos enemigos buscaron la guerra: El desenlace histórico no podía ser otro que el golpe.

A diferencia de lo que ha ocurrido en Chile, en el mundo, y desde muy temprano, se estabilizó un juicio condenatorio mundial del golpe de Estado en Chile. La noción de pronunciamiento militar ni siquiera es conocida fuera de sus fronteras. La admiración por Pinochet se concentra en los mismos cuestionables líderes que admiran a Franco, Mussolini o al propio Hitler. Al inventario de las rarezas ha entrado la diferencia de Hayek entre totalitarismo como el de estos y autoritarismo de un Pinochet, ampliamente compatible con las libertades individuales. Los movimientos de protesta y sabotaje contra el gobierno de la UP fueron difícilmente comprendidos como desobediencia civil. Más bien fueron enjuiciados como sediciosos, es decir, como orientados no a la ampliación o restauración de derechos si no a la reinstauración de los intereses económicos de las clases dominantes criollas y de los EEUU. El caso de Chile es uno entre los varios que obligan a que intelectuales, como Rawls, deban separar entre la noción ideal democracia liberal razonable de este país y los EEUU real. Es otro de los ejemplos — el, más olvidado, es el de Costa Rica- que echan por tierra la creencia de que una democracia no ataca a otra. El eco del golpe de Estado en Chile es, sin embargo, algo más que otro ejemplo_-junto al de Brasil, de Uruguay, de Argentina y de Bolivia, etc. - en las olas de subversión y dictadura en América Latina. El Chile de Allende - la vía chilena al socialismo- era un “experimento crucial” que trataba de falsear lo ampliamente aceptado: que era imposible conducir a un país hacia un socialismo revolucionario sin salirse de la democracia constitucional. El éxito de un tal experimento hubiese sido una lección demasiado peligrosa para el occidente capitalista, sobre todo para países europeos como la Italia de la época. Para EEUU Chile podía ser el virus que podría producir un contagio global. Una vía revolucionaria armada, a la cubana, hubiese sido menos contagiosa, pues no prometía y no contenía el ideal normativo de la democracia. Santiago era tan peligroso para EEUU como Praga para la URSS.

En este contexto es en el que Allende entra a la historia mundial bajo la figura de un héroe; lugar del que Víctor Farías y otros lo quisieran destronar. De la lectura de estos artículos aparecen, al menos, dos figuras heroicas de Allende bien distintas. Para Sweezy — y otros hoy día como •i•ekAllende es un héroe negativo pues, no intencionalmente mostró, con su propia muerte, algo que era obvio: la imposibilidad del socialismo sin violencia. Allende es ahí un héroe quijotesco, idealista e ingenuo. Para otros, Allende es ahí un héroe trágico en un sentido muy distinto. Un demócrata intransigente: lo que muchos consideraron su error político cardinal —esto 
es el no haber cedido frente al llamado a la violencia, proveniente tanto desde adentro como desde afuera, de sus supuestos aliados como de sus enemigos - es lo que lo eleva a una figura universal. Su victoria moral resulta inseparable de su fracaso político, aquél que fue producto de los errores acusados por la mayoría de los autores de Ecos mundiales del golpe de Estado. 
Polis, Revista Latinoamericana, Volumen 13, $N^{\circ} 37,2014$

\section{Notas}

${ }^{1}$ Escuela de Sociología, Universidad Andrés Bello, Santiago de Chile; Groupe de Sociologie Politique et Morale, EHESS, Paris, Francia. Mauro.basaure@gmail.com. Reseña realizada en el marco del proyecto Fondecyt regular 1140344 y del proyecto Núcleo Acciones Colectivas en Chile (1990-13/N. 2015), DI-446

${ }^{2}$ Patricio Silva parece retomar esta tesis años más tarde. Silva, Patricio (2006) "The Politics of Neo-liberalism in Latin America: Legitimacy, Depoliticization and Technocratic Rule in Chile” en The Neo-Liberal Revolution. Forging the Market State, R. Robinson, editor. London: Palgrave Macmillan, pp. 39-57.

${ }^{3}$ En cierta medida es en este marco que cabe entender la contribución de Renato Cristi y Carlos Ruiz, quienes han estudiado la "síntesis conservadora” en el Chile de la dictadura y la post-dictadura. Se trata de esa especial fusión ideológica entre nacionalismo, corporativismo y neoliberalismo, según la que el proyecto de la dictadura no era ni la mera eliminación del socialismo, ni menos la restauración de la democracia o del sistema democrático liberal, sino que más bien la realización hegemónica de dicha síntesis conservadora. Renato Cristi y Carlos Ruiz (1992) El pensamiento conservador en Chile. Santiago: Universitaria.

${ }^{4}$ Al respect es interesante: Soule, Sarah "Diffusion Processes within and across Movements”. En: The Blackwell Companion to Social Movements. D. Snow, S. Soule y H. Kriesi (eds.). Oxford: Blackwell, 294-310.

${ }^{5}$ El propio Sigmund se vió forzado a revisar sus tesis, cuestión que hizo en un artículo de 1976, "U.S. policy toward Chile”, Latin American research Rev. 11: 121-127. La discusión fue continuada con Petras y Morley: Ver: Petras, James y Morris Morley (1978) "On the U. S. and the overthrow of Allende: a reply to professor Sigmund's criticism”, Latin American research review. xiii, 1, 205-221; Sigmund, Paul (1978) "Response to Petras and Morley", Latin American research review, xiii, 1, 222-224. 